\begin{tabular}{l}
\hline \hline \\
\hline \hline $13^{\text {th }}$ International Conference on \\
AEROSPACE SCIENCES \& AVIATION TECHNOLOGY, \\
ASAT- 13, May 26 - 28, 2009, E-Mail: asat@mtc.edu.eg \\
Military Technical College, Kobry Elkobbah, Cairo, Egypt \\
Tel : +(202) 24025292 - 24036138, Fax: +(202) 22621908
\end{tabular}

\title{
Interactive Analysis of Closed Loop Electro-hydraulic Control Systems
}

\author{
Medhat k. Bahr Khalil*, Ph.D.
}

\begin{abstract}
Without exhaustive system simulation, using full featured software, predicting electro-hydraulic control system performance represents a challenge for many system designers. In this paper, an introductory study has been presented as a preliminary stage for an ultimate goal, which is developing cost effective Interactive Electro-hydraulic Closed Loop System Analyzer (IEHCLSA). IEHCLSA is software aiming ultimately, through several modules in further developments, to solve for the static and dynamic characteristics of a controlled hydraulic actuator in a feedback loop fashion.

This study shows in a systematic calculation approach how to properly calculate the pressure, flow and power required to achieve certain acceleration/deceleration rate while a cylinder is moving. The study will be associated with the first version of the software, which will be used to solve this part of the problem interactively. The following set of design parameters will be used as inputs to the stream of the calculations, the hydraulic cylinder dimensions, equivalent moving mass, volumes of the hydraulic lines, hydraulic fluid bulk modulus, required deceleration/acceleration rate and the external force distribution over the cylinder stroke. The calculation outcome will be hydraulic cylinder stiffness, natural frequency, flow and pressure requirements. Using such software may reduce the effort, time and cost of hydraulic system prototyping.
\end{abstract}

Keywords: Position, Control, Electrohydraulic, Software, Proportional, Servo

\section{Nomenclature}

$\mathrm{A}, \mathrm{A}_{1} \& \mathrm{~A}_{2}=$ Cylinder effective area, $\mathrm{m}^{2}$

$\mathrm{a}_{\max }=$ Maximum acceleration, $\mathrm{m} / \mathrm{s}^{2}$

$\mathrm{C}, \mathrm{C}_{1} \& \mathrm{C}_{2}=$ Equivalent stiffness of a confined oil volume, $\mathrm{N} / \mathrm{m}$

$\mathrm{C}_{\mathrm{H}}\left(\mathrm{C}_{\mathrm{Hmin}}\right)=$ Total stiffness of a hydraulic cylinder (minimum), $\mathrm{N} / \mathrm{m}$

\footnotetext{
* Director of Professional Education, Milwaukee School of Engineering 1025 North Broadway, Milwaukee, WI, 53202-3109, USA, halil@msoe.edu Tel: 414-940-2232 Fax: 414-277-7470
} 


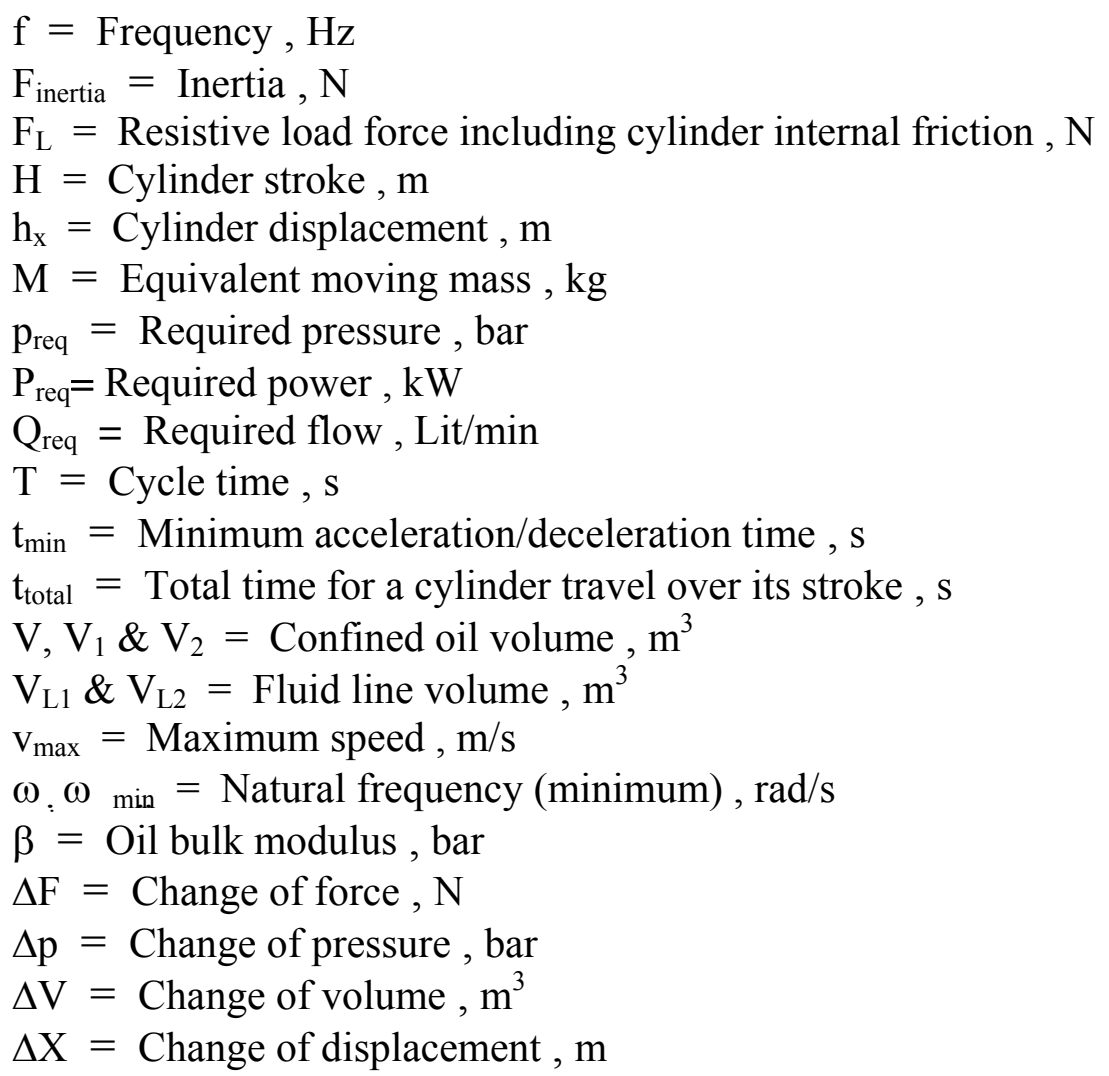

\section{1- Introduction}

Nowadays industrial and mobile machines are multi-axis machines. A quite good percentage of them, particularly of large power, are driven electro-hydraulically and controlled by proportional or servo valves.

Each axis motion can be operated in an "open loop" or "closed loop" control environment, depending on the accuracy level required in the application and the characteristics of the devices implemented in the system. The following introduction is important to clarify some terminologies, which will be used in the text. In many applications the motion cycles are slow; do not require extreme accuracy and the devices used are offering stable and of almost linear characteristics. In such cases, an open loop control system would be a simple and cost effective solution. A closed loop control system is required whenever the system dynamics is nervous and the required accuracy level is high. The accuracy of the closed loop controls is much better than the open loop ones and it is less influenced by the external disturbances.

Both open loop and closed loop control system is working based on a reference "input" signal. Setting the reference signal is generally by one of two ways, manually or automatically. Manual setting of a reference signal is usually by a mechanical lever, conventional potentiometers or joysticks. Automatic setting of the reference signal is usually by a programmable logic controller PLC, central processing units CPU in the computer-based controlled systems or by a mechanical 
Paper: ASAT-13-HC-01

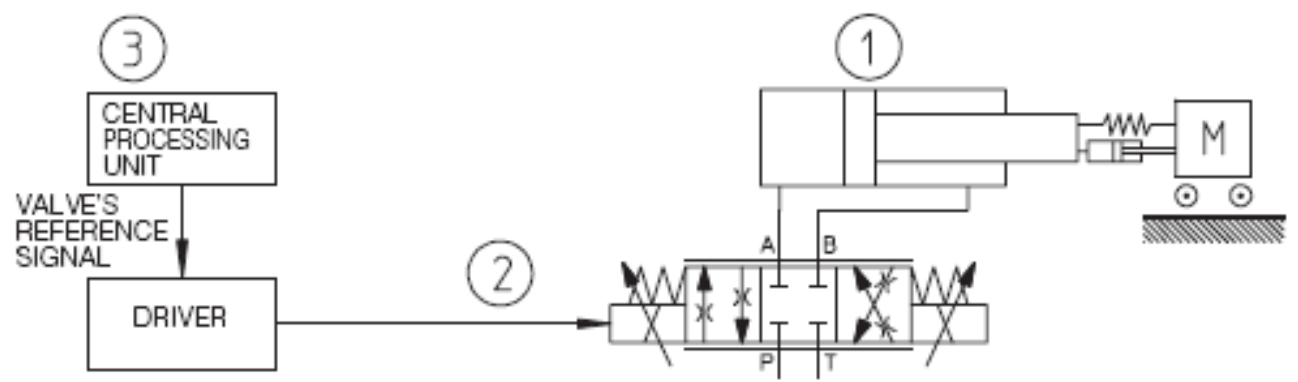

Fig.1 Automatic Open Loop Control of a Hydraulic Cylinder, Courtesy of Festo[1]

means e.g. came surface and roller. Figure 1 represents typical example of an "Automatic Open Loop" control system. As shown in the figure, the motion of a hydraulic cylinder " 1 " is controlled by a proportional valve "2". The proportional valve solenoid is receiving driving electrical current from a driver card, which is generating the driving current based on a reference "input" signal supplied directly by a CPU "3". Such system can be used only for controlling cylinder speed and force. To control a cylinder position automatically, the system must be of closed loop type with a device monitoring the cylinder position on a continuous base.

A closed loop system, whither the reference signal is set manually or automatically, can perform control of cylinder position, speed and force. Figure 2 represents typical example of an "Automatic Closed Loop" control system. As shown in the figure, the position of a hydraulic cylinder " 1 " is controlled by a proportional valve " 2 ". The proportional valve solenoid is receiving driving electrical current from a driver card, which is generating the driving current based on a control signal supplied by an axis controller. The axis controller responsibility is to continuously compare the reference signal set by the CPU " 3 " to the actual cylinder position fed back by the position sensor " 4 ", then consequently generate the adequate control signal.

Whither the loop is closed or open, manually operated system can be used to control cylinder position since the operator is closing the loop using his eyes as a feedback sensor and his brain as a controller and CPU. Typical example of this situation is an operator is moving an excavator arm. In whole cases, specifying the hydraulic power requirements in terms of flow and pressure to achieve certain acceleration/deceleration rates is an essential part of closed loop control system design. In the following, a systematic calculation approach will be presented and followed by a software tool to mechanize the calculation and end up with an interactive tool for quick system sizing.

Lumped parameter approach will be followed in this paper to parameterize the system. As shown in Fig.3, in this text, the cylinder with the attached load is defined as the hydro-mechanical part of the system. The rest of the system is defined as the electro-hydraulic. The mass $\mathrm{M}$ represents the equivalent moving mass of the hydro-mechanical part. It is the sum of the mass attached to the cylinder rod plus the mass of the cylinder piston and rod. The stiffness $\mathrm{C}$ represents the equivalent stiffness of the hydro-mechanical part. It is the combined stiffness of the physical 


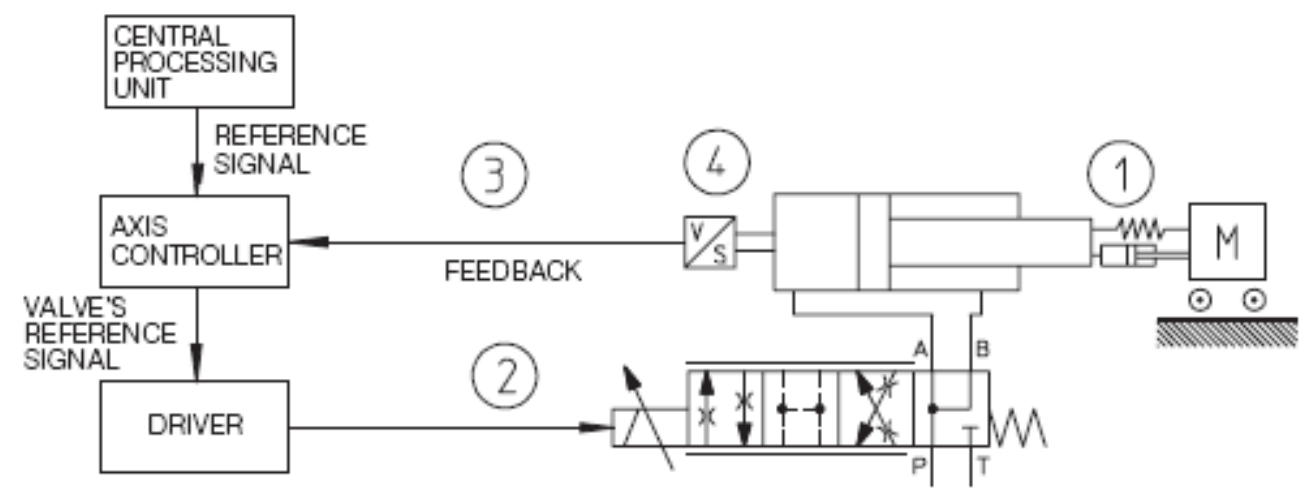

Fig.2 Automatic Closed Loop Control of a Hydraulic Cylinder, Courtesy of Festo[1]

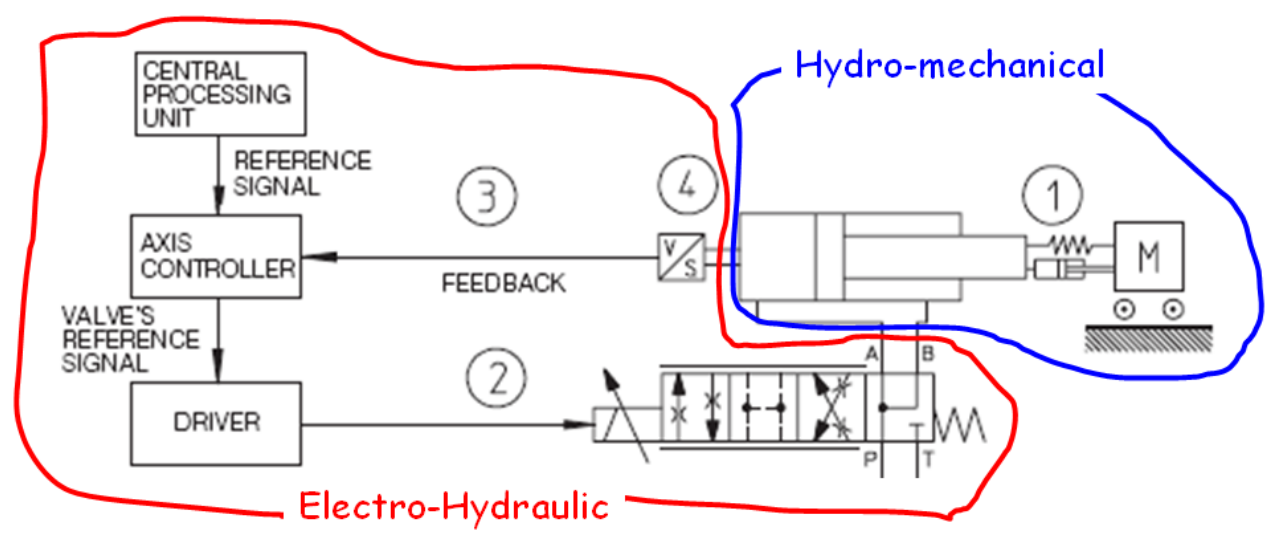

Fig.3 Electro-hydraulic and Hydro-mechanical Part of the System

spring and the cylinder stiffness due to the oil bulk modulus. The friction coefficient $\mathrm{K}$ is the equivalent friction coefficient of the hydro-mechanical part. It is the combined friction coefficient due to the piston seal friction and friction between the external moving mass and a fixed surface.

\section{2- Natural Frequency}

As shown in Fig.4, it is known that the natural frequency $\omega_{n}$ of a stable system is the frequency by which a system freely oscillates after being hit by an impulsive force until it reaches back to its steady state conditions.

Natural frequency of a system can be identified experimentally in different ways. The system can be subjected to an impulsive force and its response is acquired. The system natural frequency will be $\omega_{n}=2 \pi / T$, where $T$ is the time period of a complete oscillation. Other way is to energize the system with a harmonic input signal, start with low frequency and increase it until the system reaches a resonant condition. Frequency that causes resonance is the system natural frequency. 

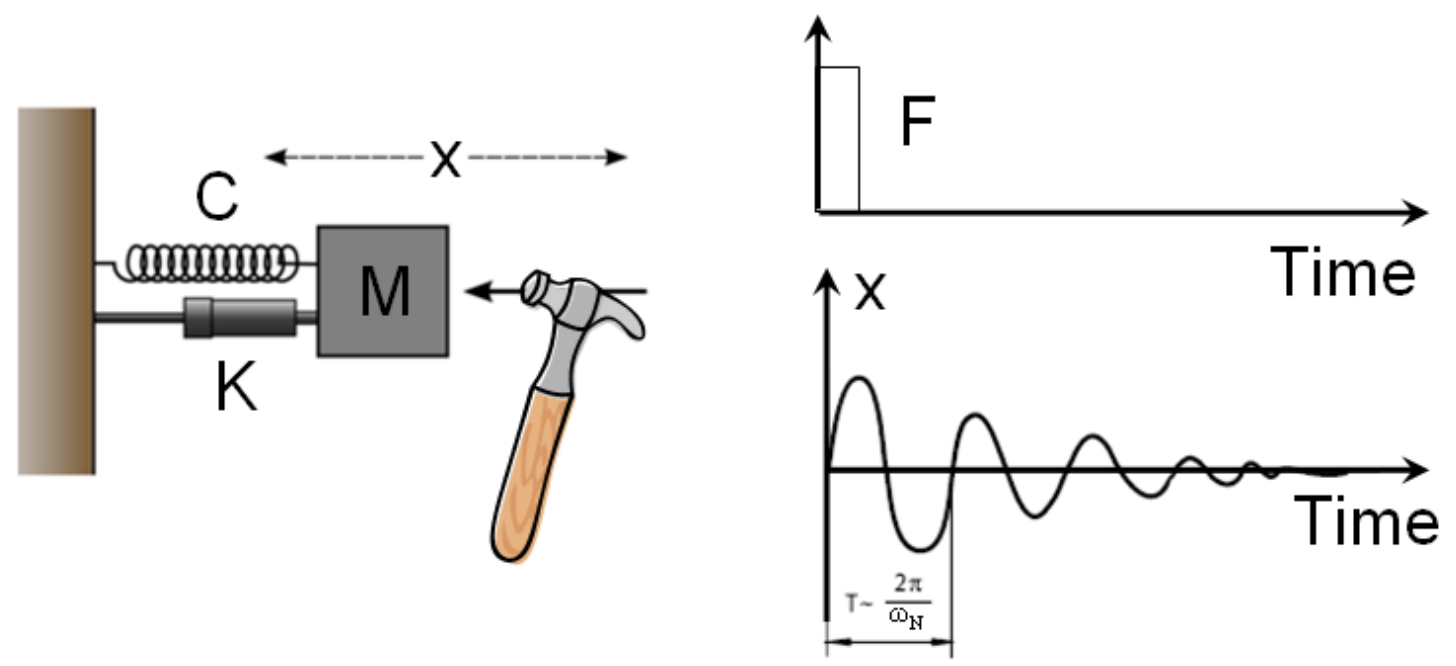

Fig.4 Natural Frequency

Natural frequency can be also calculated based on the system design parameters. Figure 2 shows a number of elements that form a closed loop to control hydraulic cylinder position. Each of these elements has its own natural frequency. The feedback sensor has usually natural frequency 10 times higher than the cylinder. Obviously the valve has higher frequency as compared to the cylinder due its small spool mass. The electronic driver is of the highest natural frequency among these elements. Then the natural frequency for the overall system equals the natural frequency of the hydro-mechanical part since it has the minimum natural frequency among the other system elements. Therefore, an electro-hydraulic controlled system natural frequency will be

$$
\omega_{\mathrm{N}}=\sqrt{\mathrm{C} / \mathrm{M}}=2 \pi \mathrm{f}=2 \pi / \mathrm{T}
$$

Where $\mathrm{C}$ and $\mathrm{M}$ are the equivalent stiffness and moving mass of the hydro-mechanical part of the system; respectively and $f$ is the frequency.

\section{3- Hydraulic Cylinder Stiffness}

In order to calculate the natural frequency of a hydraulic cylinder, the hydraulic cylinder stiffness must be found in advance.

Figure 5 shows a hydraulic cylinder of differential (unequal area) on both sides of the cylinder piston where $A_{1}$ is the cylinder bore area and $A_{2}$ is the annulus effective area at the rod side. As shown in the figure, this cylinder can be simulated by a mass attached to two springs in series arrangement. In such arrangement, the total stiffness of the cylinder is the sum of $C_{1}$ and $C_{2}$. Starting with the definition of the stiffness, the hydraulic stiffness of a confined volume of oil under pressure in a cylinder chamber can be deduced as follows:

$$
\mathrm{C}=\frac{\Delta \mathrm{F}}{\Delta \mathrm{X}}=\frac{\Delta \mathrm{p} \times 10^{5} \times \mathrm{A}}{\Delta \mathrm{X}}=\frac{\Delta \mathrm{p} \times 10^{5} \times \mathrm{A}^{2}}{\Delta \mathrm{V}}=\frac{\beta \times 10^{5} \times \mathrm{A}^{2}}{5 / 10}
$$




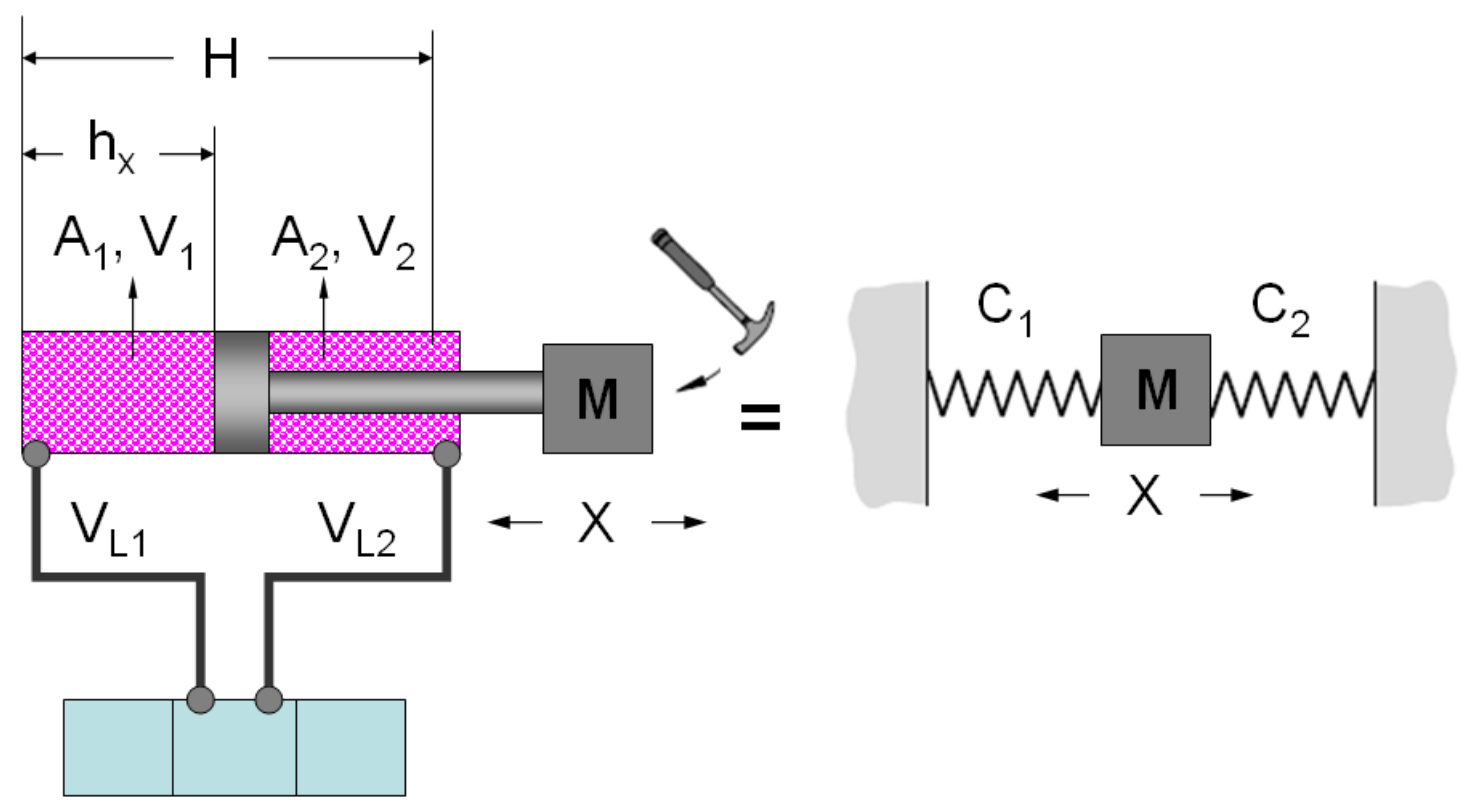

Fig.5 Simulating Hydraulic Cylinder Stiffness

Where $\beta$ is the oil bulk modulus, $\mathrm{A}$ is the effective area under pressure, $\mathrm{V}$ is the sum of the dynamic volume of the corresponding cylinder chamber plus the dead volume of the fluid line connected to that chamber.

Applying equation 2 to the two cylinder chambers, values of $\mathrm{C}_{1}$ and $\mathrm{C}_{2}$ are found as follows:

$$
\begin{aligned}
& C_{1}=\frac{\beta \times 10^{5} A_{1}^{2}}{V_{1}+V_{L 1}} \\
& C_{2}=\frac{\beta \times 10^{5} A_{2}^{2}}{V_{2}+V_{L 2}}
\end{aligned}
$$

The total stiffness of a differential cylinder would then be

$$
\mathrm{C}_{\mathrm{H}}=\beta \times 10^{5}\left[\frac{\mathrm{A}_{1}^{2}}{\mathrm{~V}_{1}+\mathrm{V}_{\mathrm{L} 1}}+\frac{\mathrm{A}_{2}^{2}}{\mathrm{~V}_{2}+\mathrm{V}_{\mathrm{L} 2}}\right]
$$

The volumes $\mathrm{V}_{1}$ and $\mathrm{V}_{2}$ are dynamic volumes based on the cylinder piston position. A mathematical manipulation has been carried out by [2] to find out the total stiffness of a differential hydraulic cylinder versus its stroke $\mathrm{H}$.

As it can be seen from Figure 6, stiffness is high when the cylinder is dead headed at either end of the strokes. Stiffness reaches a minimum approximately at cylinder travel $h_{x}=0.56 \mathrm{H}$. Substituting value of $h_{x}$ in equation 5 , minimum stiffness for differential cylinder will be 


$$
\mathrm{C}_{\mathrm{Hmin}}=\beta \times 10^{5}\left[\frac{\mathrm{A}_{1}^{2}}{0.56 \mathrm{HA}_{1}+\mathrm{V}_{\mathrm{L} 1}}+\frac{\mathrm{A}_{2}^{2}}{0.44 \mathrm{HA}_{2}+\mathrm{V}_{\mathrm{L} 2}}\right]
$$

In case of synchronous cylinder (double rod of equal area) $A_{1}$ equal $A_{2}$. As shown in Fig.7, the minimum stiffness will be exactly at the middle of the cylinder stroke. Therefore, equation 6 would be

$$
\mathrm{C}_{\mathrm{H} \min }=\beta \times 10^{5}\left[\frac{\mathrm{A}^{2}}{0.5 \mathrm{HA}+\mathrm{V}_{\mathrm{L} 1}}+\frac{\mathrm{A}^{2}}{0.5 \mathrm{HA}+\mathrm{V}_{\mathrm{L} 2}}\right]
$$

Assuming the hydraulic fluid lines are of small volumes, equations 6 and 7 will become 8 and 9 , respectively.

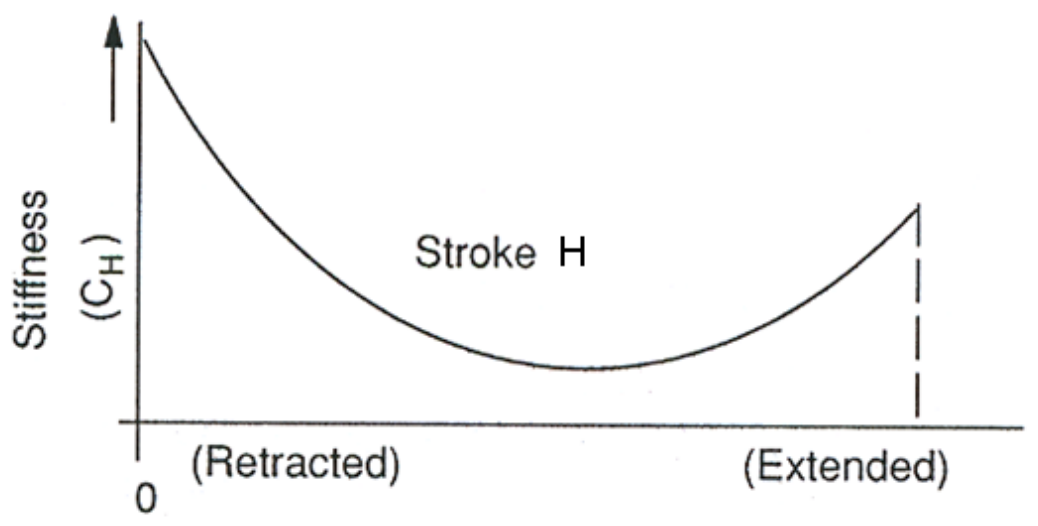

Fig.6 Hydraulic Differential Cylinder Stiffness versus Stroke, Courtesy of Vickers [2]
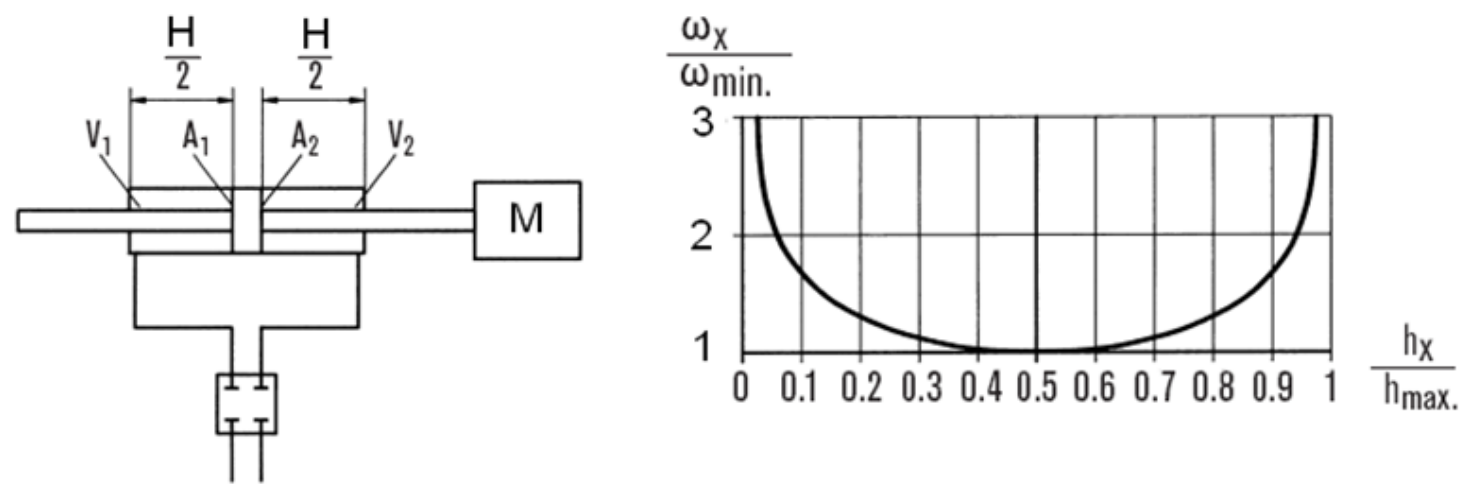

Fig.7 Hydraulic Synchronous Cylinder Stiffness versus Stroke, Courtesy of Bosh [3] 


$$
\begin{aligned}
\mathrm{C}_{\mathrm{Hmin}} & =\frac{\beta \times 10^{5}}{\mathrm{H}}\left[\frac{\mathrm{A}_{1}}{0.56}+\frac{\mathrm{A}_{2}}{0.44}\right] \\
\mathrm{C}_{\mathrm{H} \min } & =\frac{4 \beta \mathrm{A} \times 10^{5}}{\mathrm{H}}
\end{aligned}
$$

For performance calculation, only the minimum stiffness will be considered since it has the worst effect on the system dynamics. By substituting the value of the minimum stiffness in equation 1, the minimum natural frequency will be

$$
\omega_{\mathrm{Nmin}}=\sqrt{\mathrm{C}_{\mathrm{H} \min } / \mathrm{M}}
$$

\section{4- Hydraulic Cylinder Maximum Acceleration and Deceleration}

Closed system designer goal is to achieve maximum possible acceleration/deceleration rate so that the system will respond very fast to an input signal. On the other hand, the very responsive system may be nervous and unstable. A compromise must be made between the system stability and its speed of response, or in other words minimum acceleration/deceleration time. A rule of thumb has been introduced by [1] and [2] to assure the motion stability. The rule of thumbs said that the minimum acceleration/deceleration time is to be approximately not less than five times $\mathrm{T}$ at the natural frequency. Using equation1, minimum acceleration/deceleration time would be approximately

$$
\mathrm{t}_{\text {min }}=35 / \omega_{\mathrm{Nmin}}
$$

The minimum natural frequency has been used to assure the stability over the whole cylinder stroke.

Once the cylinder stroke and the total time for this stroke are known, maximum speed can be calculated, with the aid of Fig. 8, as follows

$$
\begin{aligned}
& \mathrm{H}=0.5 \mathrm{t}_{\text {min }} \times \mathrm{v}_{\text {max }}+\mathrm{v}_{\text {max }}\left(\mathrm{t}_{\text {total }}-2 \mathrm{t}_{\text {min }}\right)+0.5 \mathrm{t}_{\text {min }} \times \mathrm{v}_{\text {max }} \text { then } \\
& \mathrm{v}_{\text {max }}=\mathrm{H} /\left(\mathrm{t}_{\text {total }}-\mathrm{t}_{\text {min }}\right)
\end{aligned}
$$

Consequently, maximum acceleration can be calculated as follows

$$
\mathrm{a}_{\text {max }}=\mathrm{v}_{\text {max }} / \mathrm{t}_{\text {min }}
$$

\section{5- Hydraulic Power Requirements}

Equations 14 through 17 show the calculation of the inertia, required pressure, required flow and required power source size; respectively. Those set of equations must be solved twice to find out the hydraulic power requirements that satisfy both extension and retraction cylinder stroke. 


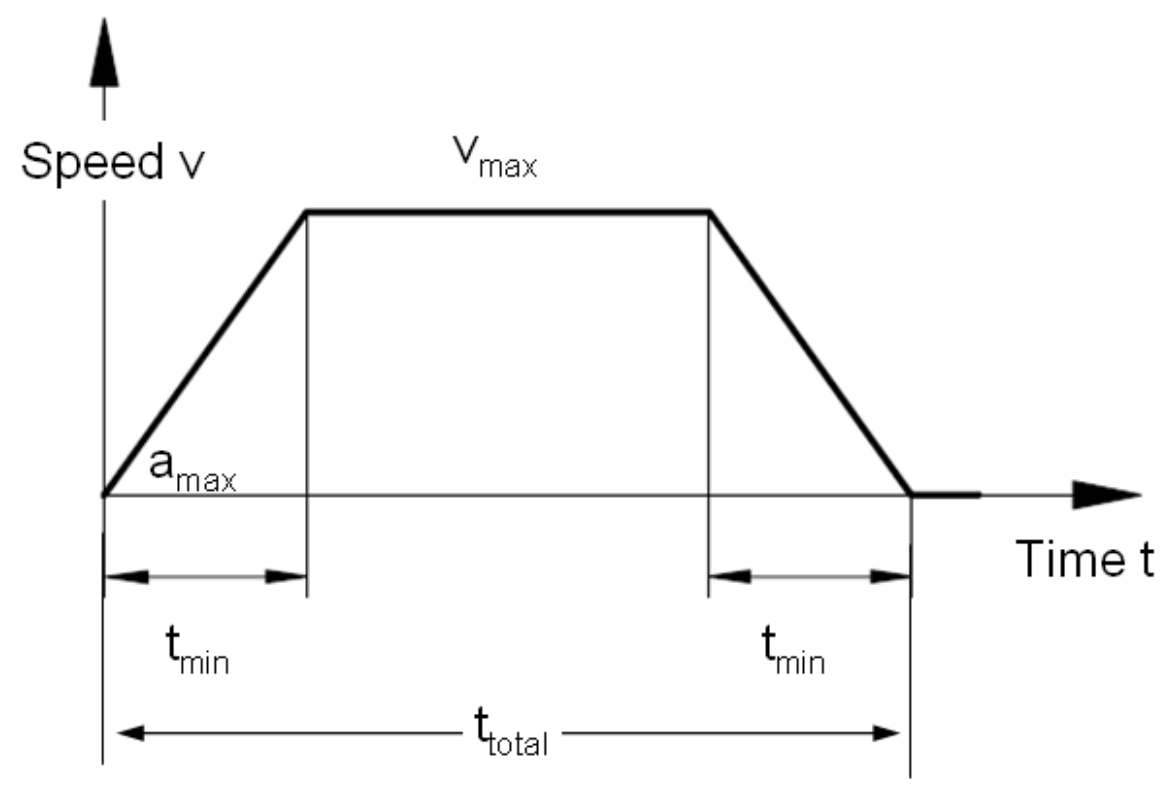

Fig.8 Hydraulic Cylinder Work Cycle

$$
\begin{aligned}
& \mathrm{F}_{\text {inertia }}=\mathrm{M} \times \mathrm{a}_{\text {max }} \\
& \mathrm{p}_{\text {req }}=\left(\mathrm{F}_{\text {inertia }}+\mathrm{F}_{\mathrm{L}}\right) /\left(\mathrm{A} \times 10^{5}\right) \\
& \mathrm{Q}_{\text {req }}=\mathrm{v}_{\text {max }} \times \mathrm{A} \times 60000 \\
& \mathrm{P}_{\text {req }}=\mathrm{p}_{\text {req }} \times \mathrm{Q}_{\text {req }} / 600
\end{aligned}
$$

\section{6- Interactive Electro-Hydraulic Closed Loop System Analyzer}

As shown in Fig.9, the first version of the software is developed to solve the aforementioned set of equations interactively for the extension stroke of a differential cylinder. Equations 6 and Equations 10 through 17 are solved sequentially to help estimating the hydraulic power source required to move a hydraulic cylinder in a stable motion.

\section{7- Conclusion}

In this paper, a study has been made to analyze the hydraulic power requirements for a stable motion of a hydraulic cylinder. The study is important as introductory part for a closed loop control of a hydraulic cylinder motion.

The calculation approach presented in this paper has been applied for a hydraulic cylinder; it is applicable for hydraulic motors as well as the rotary actuators.

Future works are as follow: 


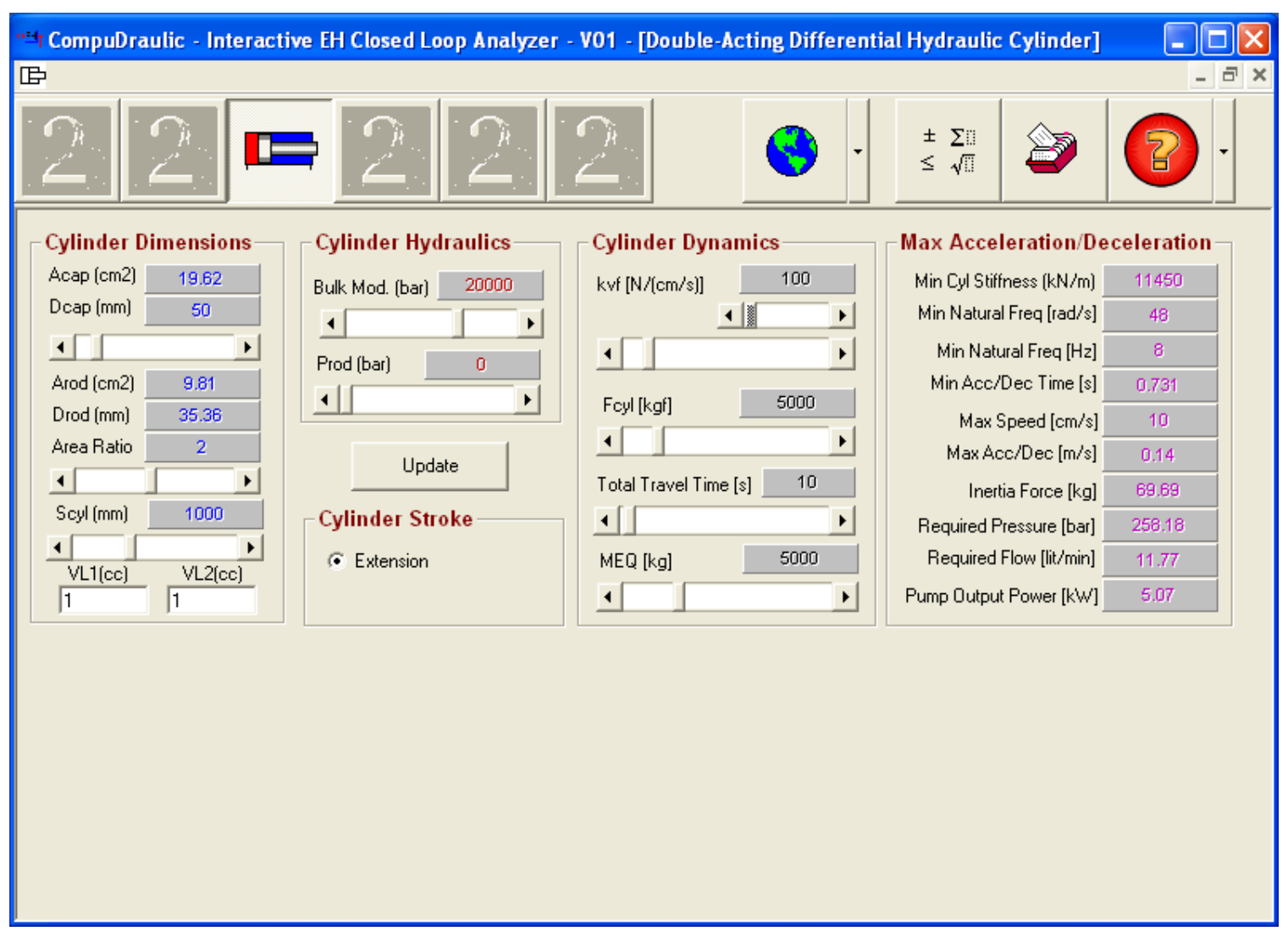

Fig.9 Interactive Electro-Hydraulic Closed Loop System Analyzer, Version 1

By knowing the natural frequency, friction and equivalent moving mass, the cylinder transfer function can be found and stability analysis can be made.

Extend the feature of the software to include full closed loop analysis e.g. controller parameter estimations, stability analysis, step response analysis, frequency response analysis, overall system stiffness and existing system definition.

By using the developed software, rule of thumbs and design charts can be developed Apply the same concept for other hydraulic actuators like hydraulic motor and rotary actuator

\section{8- References:}

[1] Proportional Hydraulics Textbook, Festo Didactic GmbH \& Co., 73770 Denkendorf / Germany, 2002.

[2] Closed Loop Electrohydraulic systems Manual, Copyright 1992 by Vickers, Incorporated. ISBN 0-9634162-1-9.

[3] Electrohydraulic Proportional and Control Systems, Copyright 1999 OMEGON Fachliterature, Germany, ISBN 0-7680-0538-8. 